\section{Osteopetrosis: a rare cause of anemia}

\author{
Sreekala Sreehari, Divya Rani Naik, \\ Malini Eapen
}

Amrita Institute of Medical Sciences, Kochi, India

\section{Abstract}

Normocytic anaemia is caused either by hypoproliferation of haemopoietic tissue or increased destruction of red cells. 0steopetrosis is a rare cause of anaemia. Infantile osteopetrosis (also called malignant osteopetrosis) is diagnosed early in life. But it is the adult osteopetrosis (also called benign osteopetrosis) which is diagnosed in late adolescence or adulthood that present as anaemia which is difficult to diagnose and treat. Approximately one half of patients are asymptomatic, and the diagnosis is made incidentally, often in late adolescence because radiologic abnormalities start appearing only in childhood. In other patients, the diagnosis is based on family history. Still other patients might present with osteomyelitis or fractures. We are presenting here an unusual case of osteopetrosis which was referred to us for the evaluation of anaemia.

\section{Case Report}

A 47-year old gentleman was admitted with history of anemia, lower abdominal pain and loose stools of $11 / 2$ months duration. He also had history of spastic paresis and generalized weakness since 6 months. He had no history of anorexia or significant weight loss, any bone pains, recurrent infection, bleeding manifestation or fracture. No history of fever, jaundice or GI bleeds. His family history was unremarkable. He was evaluated at another hospital for 6 months and was managed conservatively. He was pale, conscious, and afebrile with paresis of both the lower limbs. His height was $158 \mathrm{~cm}$, and no skeletal deformities were found during his physical examination. His vitals were normal and he had mild hepatosplenomegaly.

Hematological investigations showed $\mathrm{Hb}$ of $8 \mathrm{~g} / \mathrm{dL}$, WBC $7.75 \mathrm{k} / \mathrm{uL}$, platelet count $130 \mathrm{k} / \mathrm{uL}$ and ESR was $60 \mathrm{~mm} / 1 \mathrm{st}$ hour. Red cell indices and iron profile were normal. Peripheral smear showed normocytic normochromic anemia. Malaria, Kala-azar and chronic hemolytic anemia were excluded by relevant tests.

Renal function and serum electrolytes were within normal limits (creatinine $1 \mathrm{mg} / \mathrm{dL}, \mathrm{Na}$ $134 \mathrm{meq} / \mathrm{K}$ K3.3 mmol/L). His liver function were normal (total bilirubin $0.7 \mathrm{mg} / \mathrm{dL}$, SG0T22.7 IU/L/, SGPT 15.8 IU/L, ALP 84.8IU/L, total protein $8 \mathrm{gms} / \mathrm{L}$, albumin $3.6 \mathrm{~g} / \mathrm{dL}$ and globulin $4 \mathrm{gms} / \mathrm{L}$ ).

His serum calcium was $8.5 \mathrm{mg} / \mathrm{dL}$, inorganic phosphate $3.1 \mathrm{mg} / \mathrm{dL}$, alkaline phosphatase $84.8 \mathrm{IU} / \mathrm{L}$. Intact parathyroid hormone 820 pguml, TSH 1.89IU/L, T41.09, intact osteocalcin $175.7 \mathrm{ng} / \mathrm{mL}$ and prostatic specific antigen $0.5 \mathrm{ng} / \mathrm{mL}$. HIV, HBSAg and HCV were negative. PT and APTT were within normal limits. CRP was $0.74 \mathrm{mg} / \mathrm{L}$.

Upper GI endoscopy and biopsy showed mild antral gastritis. Rapid urease test was negative. Colonoscopy showed haemorrhoids.

MRI spine showed straightening of cervical spine with marginal osteophytes. Diffusely altered vertebral marrow signal intensities seen in all visualized vertebrae appearing hypointense on $\mathrm{T} 1$ and $\mathrm{T} 2$ images suggestive of sclerosis. Variable desiccation of the inter vertebral discs seen. No significant disc bulges seen. Brainstem and cervical cord appeared normal. Craniovertebral junction appeared normal. Pre and paravertebral soft tissue was normal. Screening of lumbar spine revealed desiccation and diffuse bulge of L4-L5 intervertebral disc intending thecal sac and narrowing of bilateral neural foramen.

Final impression: diffuse sclerosis of vertebra, possibility of metastasis or myelosclerosis to be ruled out. Diffuse bulge of L4-L5 disc intending thecal sac and narrowing bilateral neural foramen.

Bone marrow aspirate was dilute and showed only minimal cellularity. Bone marrow biopsy showed a variably cellular marrow. Mild compromise of marrow spaces was seen with thickened bony trabeculae. There was lesser degree of disorganization of bony trabeculae accompanied by mild fibrosis of bone marrow spaces. Erythroid series showed normoblastic maturation. Myeloid series showed all stages of maturation, with mild dyspoiesis. Megakaryocytes were adequate with few hypolobated forms and focal clustering. Markedly thickened bony trabeculae seen with regular cement lines. Deposition of calcific debris in the cartilaginous matrix was noted. No osteoclast activity was seen. Thickened blood vessels were seen. No granuloma/ parasite. Reticulin pattern was normal. Hence a diagnosis of cellular marrow with trilineage maturation with markedly thickened bony trabeculae was made. The differentials considered were: osteopetrosis (adult type - autosomal dominant) and skeletal flurosis. His fluoride levels were within normal limits.

Based on the clinical, hematological, radiological and BMB findings the final diagnosis of osteopetrosis (adult type - autosomal dominant) was made. Genetic studies could not be performed.
Correspondence: Sreekala Sreehari, Department of Pathology, Amritha Institute of Medical Sciences, Elamakkara, Kochi, Kerala, India.

E-mail: sreekalasreehari@gmail.com

Key words: osteopetrosis.

Received for publication: 10 December 2010 Accepted for publication: 17 December 2010.

This work is licensed under a Creative Commons Attribution 3.0 License (by-nc 3.0).

(C) Copyright S. Sreehari et al., 2011

Licensee PAGEPress, Italy

Hematology Reports 2011; 3:e1

doi:10.4081/hr.2011.el

\section{Discussion}

Osteopetrosis is a disease of unknown etiology. ${ }^{1}$ It is a genetically heterogenous disorder classified as autosomal recessive and autosomal dominant type OP. ${ }^{2}$ The AR variety is also known as congenital or infantile or malignant OP occurs in infancy and has a rapid downhill course due to severe bone marrow failure. ${ }^{3,5,7}$ $\mathrm{AD}$ variety also known as benign or tarda variety is detected in older children, adolescents and adults and has a benign course due to normal bone marrow function., ${ }^{2,610}$ Cases that do not fit characteristically into the above two types on either clinical, hematological or radiological grounds have been classified as intermediate $\mathrm{OP}$. The underlying pathophysiological mechanism in all types of OP is failure of the osteoclasts to reabsorb bone, leading to thickened sclerotic bone with poor mechanical properties. Recently mutations have been identified in the ATP 6 (ICIR GI gene) encoding the a3 subunit of the vascular proton pump, which mediate acidification of the bone osteoclast interface. This defect is estimated to occur in half of the case of AR OP. A defect in the CIC-7 chloride channel has been demonstrated in minority of both $\mathrm{AR}$ and $\mathrm{AD} \mathrm{OP}$. Parental consanguinity has been frequently observed by investigators from Saudi Arabia ${ }^{6}$ while it was conspicuous by its absence in our case. In our patient pallor, mild hepatosplenomegaly and lower limb paresis were the clinical manifestation.

Given the reduced penetrance of the AD0 phenotype, the spectrum of disease expression can range from radiographically unaffected gene carriers to skeletally affected yet asymptomatic individuals to severely affected persons with multiple fractures, osteomyelitis, cranial nerve deficits, and bone marrow failure resulting from decreased volume of the medullary cavity.,10 Anemia and thrombocytopenia were found in our patient and has also 
been described in other sporadic reports from India. ${ }^{1,9}$ Bone marrow aspirate in many patients was mostly a dry tap. This can be explained on the basis of fibrosis. Subsequent bone marrow biopsy revealed the histopathological features consistent with osteopetrosis. On the basis of the degree of disorganization of bony trabeculae and effacement of hemopoeitic space by fibrous tissue, cases were classified as AD OP and AR OP. Hence BMB is essential for the final diagnosis of OP and its varieties.

On radiological examination. patients from all reports fulfilled the criteria for diagnosis of OP due to manifestation of generalized dense sclerosis of skull, vertebra and long bones. "Bone within bone" and pathological fracture were rare. "Rugger Jersey" or sandwich vertebra has been described in 50\% of cases from Costa Rica. ${ }^{8}$

The current recommended treatment of $\mathrm{OP}$ is based on its variety. In AR OP BMT is recommended along with high dose calcitriol, recombinant human gamma interferon. However in adult $\mathrm{OP}$ which has relatively normal bone marrow function no specific medical treatment exists. Therefore since BMB results have a bearing on deciding the treatment strategies, the importance of this investigation in the complete work up does not need further emphasis.

\section{References}

1. Tripathi AK, Tandon V, Kumar A, et al. A rare cause of Leucoerythroblastic anemia. India J Hematol Blood Transf 1998;16:62-4.

2. Bhargava A, Blank R. Osteopetrosis. eMedicine from WebMD (Endocrinology). Available at: http://emedicine.medscape. com/article/123968-overview. Last updated: October 13, 2009.

3. Bodamer OA, Braverman RM, Craigen WJ. Multiple fractures in a 3-month-old infant with severe infantile osteopetrosis $\mathrm{J}$ Pediatr Child Health 2001;37:520-2.

4. Bénichou OD, Laredo JD, de Vernejoul MC. Type II AD osteopetrosis; clinical and radi- ological manifestations in 42 patients. Bone 2000;26;87-93.

5. Chen CJ, Lee MY, Hsu ML, et al. Malignant infantile OP initially presenting with neonatal hypocalcaemia: Case report. Ann Hematol 2003;82:64-7.

6. Mahdi AH. Osteopetrosis in Saudi children: A report of 10 cases. Ann Trop Pediatric 1988;8:112-5.

7. Stark Z, Savarirayan R. Osteopetrosis. Orphanet Journal of Rare Diseases 2009; 4:5.

8. Loria-Cortes R, Quesada-Calvo E, CorderoChaverri C. Osteopetrosis in children: A report of 26 cases. J Pediatr 1977;91:43-7.

9. Kumar P, Shashi Kala P, Chandrashekhar HR, Basavargin Band AS. Osteopetrosis presenting as leuko-erythroblastic anemia: A case report. Indian J Haematol Blood Transf 1998;116:260-1.

10. Sharma A, Kumar S. Ostepetrosis tarda: A case report. J Indian Med Assoc 1999;97: $22-4$. 